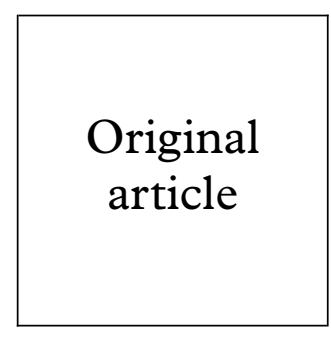

\title{
Community based study of sexually transmitted diseases in rural women in the highlands of Papua New Guinea: prevalence and risk factors
}

\author{
M Passey, C S Mgone, S Lupiwa, N Suve, S Tiwara, T Lupiwa, A Clegg, M P Alpers
}

Objective: To estimate the prevalence of sexually transmitted diseases (STDs) and determine their risk factors/markers among a rural population of women in the highlands of Papua New Guinea.

Methods: Community based random cluster sample of women of reproductive age were interviewed and examined and had specimens collected for laboratory confirmation of chlamydial and trichomonal infection, gonorrhoea, syphilis, and bacterial vaginosis.

Results: Chlamydia trachomatis was detected in $26 \%$, Trichomonas vaginalis in $46 \%$, Neisseria gonorrhoeae in $1 \%$, syphilis in $4 \%$, pelvic inflammatory disease (PID) (diagnosed clinically) in $14 \%$, and bacterial vaginosis in $9 \%$ of 201 women. $59 \%$ of the women had at least one STD. In a multivariate logistic regression analysis taking the clustered sampling into account, independent risk factors for chlamydial infection were age $\leqslant 25$ years, $<$ four living children, visualisation of yellow mucopurulent endocervical secretions on a white swab, and bacterial vaginosis. Being married to a man who did not have other wives was protective. For trichomonal infection, independent risk factors were having no formal education, infertility, more than one sexual partner in the previous 12 months, treatment for genital complaints in the previous 3 months, abnormal vaginal discharge detected on examination, and chlamydial infection. Similar levels of trichomonal infection were found in all age groups. Among married women, rates of infection correlated with their perception of their husband having had other sexual partners in the previous 3 months, and this relationship was significant for chlamydial infection among women over 25 .

Conclusion: STDs are a major problem in this population, with the risk factors varying by outcome. Current treatment regimens are inappropriate given the high prevalence of trichomonal infection, and the available services are inadequate. Effective interventions are required urgently to reduce this burden and to prevent the rapid transmission of HIV.

(Sex Transm Inf 1998;74:120-127)

Keywords: STDs; Chlamydia trachomatis; Trichomonas vaginalis

\section{Introduction}

Sexually transmitted diseases (STDs) and other reproductive tract infections (RTIs) have received considerable attention since the advent of the HIV/AIDS epidemic. There is now ample evidence implicating STDs as cofactors in the transmission of HIV, ${ }^{12}$ as well as studies demonstrating reduced transmission of HIV with improved treatment of STDs. ${ }^{34}$ STDs also cause considerable morbidity and mortality of their own, an issue which may be closer to the concerns of many people in developing countries in which the HIV epidemic is in an early stage.

Papua New Guinea is fortunate in being at a relatively early stage of the HIV epidemic. Heterosexual spread is the most common mode of transmission, and cases have been confirmed from every province. ${ }^{5}$ STD clinics provide curative services in most of the provincial capitals and the national capital. Outside these towns, health centres are supposed to provide STD care but the staff are not trained to do so, and the appropriate drugs are rarely available. There is thus considerable urgency in developing and implementing effective STD and HIV control programmes. Although interventions have been initiated targeting sex workers and the transport industry, to date little effort has been directed at the majority of the population who live in rural areas.

There is a dearth of reliable information on the prevalence, aetiology, or risk factors for STDs in the general population in Papua New Guinea, although there is evidence to suggest that there is a significant burden from them. STD clinic studies have documented the presence of all the classic STDs, with probably all of these diseases having been introduced to coastal communities over the past 100 years or more of contact with outsiders, and having since spread throughout the country. There was a threefold increase in the incidence rates of reported cases of gonorrhoea and syphilis between 1974 and $1986 .{ }^{6}$ In an antenatal clinic population in Port Moresby, Klufio et al found a prevalence of chlamydial infection of $17.7 \%{ }^{7}$ No other studies on the prevalence of STDs, or the risk factors for their acquisition in a non-STD clinic population or in rural areas have been reported from Papua New Guinea.

We conducted a cross sectional community based study in a rural area of Papua New Guinea. The study population lives in the Asaro Valley, near the town of Goroka, in the Eastern Highlands Province. The people live in small villages and are mostly subsistence farmers with coffee as a cash crop, or are labourers 
on coffee plantations. Health services are provided through a network of small village aid posts, a health centre, and the provincial hospital in Goroka, which has an STD clinic.

We estimated the prevalence of STDs among women of reproductive age and the prevalence of genital chlamydial infection in adult men. We determined risk factors/markers for prevalent infection and assessed treatment seeking behaviour. Our purpose was to ascertain whether or not the current services were meeting the needs of the population and to identify risk markers and clinical variables which would aid in the identification of infected individuals given the extremely limited clinical and laboratory facilities available. Here we present the prevalence and risk factor data for the women.

\section{Methods}

PARTICIPANT RECRUITMENT

The study was conducted between April and August 1995. Ethical clearance for the study was obtained from the Medical Research Advisory Committee of Papua New Guinea. Using census data from another study, we randomly selected 16 clusters (villages) with probability proportional to size. From each cluster, we then randomly selected 18 women aged 15-45 years, and 18 men over 15 years of age, giving a total of 288 women and 288 men. Owing to the development of clan warfare affecting some of the selected villages, we completed the study in only 15 clusters where we had selected a total of 270 adults of each sex. We preselected a second person from the database to replace those who may have died or moved away since the census 1 year earlier, but in small villages this was not always possible. Those who refused to participate were not replaced.

Permission to conduct the study in each village was first obtained from community leaders. Each village was allocated a week for the study, on the first day of which we conducted a workshop, with separate sessions for women and men. The purposes of the workshop were: to increase the participants' knowledge and understanding of reproductive health; to explain the purpose of the study; to allay any concerns they might have; and to increase interest and participation. Following the workshop, we obtained consent from the randomly selected individuals. To maximise our goodwill and provide a service, unselected people normally resident in the village were included if they wished, but their data are excluded from this analysis. Only the results for the women are presented in this paper.

INTERVIEWS, EXAMINATION, AND SPECIMEN COLLECTION

Consenting women were interviewed privately in the village by a female nurse or physician in Melanesian pidgin, using standardised questionnaires. Data on sociodemographic, obstetric, and sexual history were obtained. Over the next few days, we transported women to the study clinic at our institute. The data obtained in the village were reviewed and additional data on recent and current symptoms related to the reproductive tract, and any treatment sought, were obtained. We then collected blood for syphilis serology.

Women who stated they had never had intercourse were not examined. All other women were examined by a female physician. Vaginal erythema, abnormal vaginal discharge (as perceived by the physician), its colour and consistency, and any ulcers were noted. The cervix was wiped with cotton gauze and inspected. Endocervical secretion was characterised as mucopus (cloudy) or non-mucopus (clear). Erythema or oedema of the zone of ectopy of the endocervix was noted and classified as "visible cervicitis". We then obtained swabs, in the order described, for laboratory tests. A cotton tipped high vaginal swab was collected for Gram staining. A cotton tipped endocervical swab was smeared onto GC media containing vancomycin inhibitor (Difco, USA) and onto chocolate agar, then rolled onto a glass slide for Gram staining. A Dacron endocervical swab for detection of Chlamydia trachomatis by polymerase chain reaction (PCR) was placed into phosphate buffered saline. The first endocervical swab was inspected, and if it was yellow the "swab test" was considered positive. ${ }^{8}$ If the cervix bled following removal of the first swab, it was recorded as being "friable". Bimanual palpation was performed, and the presence of adnexal, uterine, or cervical motion tenderness or pelvic masses recorded. Pelvic inflammatory disease (PID) was diagnosed clinically when three of the following were present-lower abdominal tenderness, adnexal tenderness, uterine tenderness, and cervical motion tenderness. (No laparoscopy or endometrial biopsy is available in our setting.) Couples were considered infertile if the woman reported that they wanted more children, were trying to conceive, and had had unprotected intercourse for 2 or more years. In this society cohabitation is often intermittent, particularly in the first year of marriage, so 2 years was used rather than the more standard 1 year.

\section{LABORATORY PROCEDURES}

Vaginal secretions from the speculum were used for $\mathrm{pH}$ determination, the amine or "sniff" test, and for wet mount for microscopic detection of motile trichomonads, the presence of which was considered diagnostic for infection with Trichomonas vaginalis. The smears prepared from the vaginal and endocervical swabs were Gram stained. Bacterial vaginosis (BV) was diagnosed if three of the following four criteria were met: clue cells on wet mount or Gram stain; $\mathrm{pH}>4.5$; positive amine test; and the absence of normal flora on vaginal Gram stain. The endocervical Gram stain was used for detection of Gram negative intracellular diplococci. The plates for gonococcal culture were transported in a candle extinction jar to the laboratory where they were placed in a carbon dioxide incubator at $37^{\circ} \mathrm{C}$ and read after 24 and 48 hours. Colonies were Gram stained and identified further using standard techniques. We used the culture results for the definitive diagnosis of gonococcal infection. The swabs for detection of chlamydial infection 
Table 1 Selected characteristics of the 201 women interviewed and examined, Asaro Valley, Papua New Guinea

\begin{tabular}{|c|c|c|}
\hline & Number & $\%$ \\
\hline \multicolumn{3}{|l|}{ Sociodemographic data: } \\
\hline \multicolumn{3}{|l|}{ Age (years) } \\
\hline $15-19$ & 12 & 6.0 \\
\hline $20-24$ & 46 & 22.9 \\
\hline $25-29$ & 41 & 20.4 \\
\hline $30-39$ & 76 & 37.8 \\
\hline 40 plus & 26 & 12.9 \\
\hline \multicolumn{3}{|l|}{ Marital status } \\
\hline Married, only wife & 148 & 73.6 \\
\hline Married, co-wives & 15 & 7.5 \\
\hline Single & 13 & 6.5 \\
\hline Separated/divorced/widowed & 25 & 12.4 \\
\hline Some formal education ${ }^{\star}$ & 86 & 45.7 \\
\hline Nulliparous & 39 & 19.4 \\
\hline Currently pregnant & 26 & 12.9 \\
\hline Infertile $\nmid$ & 54 & 26.9 \\
\hline \multicolumn{3}{|l|}{ Number of living children } \\
\hline 0 & 46 & 22.9 \\
\hline $1-3$ & 109 & 54.2 \\
\hline 4 plus & 46 & 22.9 \\
\hline \multicolumn{3}{|l|}{ Sexual/STD history: } \\
\hline Reported STD ever & 64 & 31.8 \\
\hline$>1$ partner in previous year & 18 & 9.0 \\
\hline Ever used condom & 15 & 7.5 \\
\hline \multicolumn{3}{|l|}{ Current symptoms: } \\
\hline Abnormal vaginal discharge or itch & 47 & 23.4 \\
\hline Lower abdominal pain & 44 & 21.9 \\
\hline
\end{tabular}

$\star 13$ women had missing data on education.

t Couples were considered infertile if the woman reported that they wanted more children, were trying to conceive, and had had unprotected intercourse for 2 or more years.

by PCR were transported to the laboratory for storage at $-70^{\circ} \mathrm{C}$ until the time of analysis. Following crude DNA extraction, PCR was performed using the method previously described by Hayes et al. ${ }^{9}$ Specimens positive by PCR were considered to be positive for $C$ trachomatis. Syphilis serology was performed using the rapid plasma reagin test (RPR) (Murex Diagnostics, Dartford) with a cut off point of 1:4. The RPR was confirmed with a Treponema pallidum haemagglutination test (TPHA) (Wellcome Diagnostics, Dartford). Active syphilis was diagnosed when both tests were positive.

\section{TREATMENT}

All women were treated at the time of examination based on the clinical findings and the wet mount examination following the standard treatment used in Papua New Guinea. Untreated infections subsequently detected by laboratory tests were treated at a follow up visit.

\section{STATISTICAL ANALYSIS}

Data were analysed using logistic regression analysis, implemented using sAS software (SAS Institute, Cary, NC, USA). Women who were menstruating at the time were excluded from analyses involving physical signs. For assessment of risk factors for infection with $C$ trachomatis and $T$ vaginalis we developed univariate and multivariate logistic regression models using generalised estimating equations for clustered binary data. ${ }^{10}$ Multivariate logistic regression models were developed by backwards elimination. ${ }^{11}$ In the final models, interaction variables were tested and diagnostic statistics calculated and reviewed. For each outcome, three multivariate models were developed, roughly corresponding to clinical situ-
Table 2 Prevalence of sexually transmitted disease (STD) and other reproductive tract infections (RTI) among 201 randomly selected women, Asaro Valley, Papua New Guinea

\begin{tabular}{lll}
\hline STD/RTI & No/total & $\%$ \\
\hline Chlamydia trachomatis & $53 / 201$ & 26.4 \\
Neisseria gonorrhoeae & $3 / 201$ & 1.5 \\
Trichomonas vaginalis & $92 / 198$ & 46.5 \\
Syphilis $\dagger$ & $8 / 201$ & 4.0 \\
Any of the above & $117 / 198$ & 59.1 \\
Pelvic inflammatory disease $\neq$ & $24 / 171$ & 14.0 \\
Bacterial vaginosis & $18 / 197$ & 9.1 \\
\hline
\end{tabular}

${ }^{\star}$ Denominators vary owing to missing data ( 3 for $T$ vaginalis; 4 for bacterial vaginosis).

tRPR and TPHA tests both positive.

$\ddagger$ Pregnant women and women whom had had hysterectomies were excluded.

ations. In the "history only" model, only sociodemographic and sexual history variables were included to simulate the information available in small health facilities where private examination is not possible. For the "history and exam" model the physical examination data are added, and the "laboratory" model uses all variables including laboratory data. Results were considered statistically significant when $p$ $<0.05$.

\section{Results}

Of the 270 women selected, 12 were no longer resident in the village and were not able to be replaced because of the small size of the village, leaving 258 women. Of these, 225 were interviewed and 203 (75\% of those selected) completed the study protocol. Two women interviewed were virgins and were therefore not examined, giving 201 women interviewed and examined. Only two of the women who attended the initial workshop refused to participate. The remainder of the nonparticipants were not present at the workshop and, although repeated messages were left for them, did not present to the study team.

The majority of the women interviewed and examined were married, being the only wife (table 1). Polygyny is acceptable in this society and $7.5 \%$ of the women reported being co-wives. The median age was 30 , and when compared with the census population, women in the 15-19 year age group were underrepresented ( $6 \%$ of women aged $15-45$ in our sample, compared with $21 \%$ in the census). Thirty six per cent of the women had only primary education and $10 \%$ had some secondary school education. Use of modern contraception was relatively low: $17 \%$ of the women had had tubal ligations and $8 \%$ reported current use of other methods. Nearly one third reported having previously had an STD, with $16 \%$ reporting an STD in the previous 3 months. Eighty six (43\%) reported some symptom related to the reproductive tract (abnormal discharge, genital itch, dysuria, dyspareunia, abnormal bleeding, or lower abdominal pain) at the time of the survey. Despite this, only 19 women $(9.5 \%)$ had gone for treatment of genital symptoms in the previous 3 months.

The prevalences of chlamydial and trichomonal infection and of PID were high (table 2). Syphilis and gonorrhoea were much 
Table 3 Univariate associations between sociodemographic data, sexual/STD history, clinical data, and infection with Chlamydia trachomatis, among 201 randomly selected women, Asaro Valley, Papua New Guinea

\begin{tabular}{|c|c|c|c|c|}
\hline & \multicolumn{2}{|c|}{$C T$ positive* } & \multicolumn{2}{|c|}{ Univariate } \\
\hline & No/total & $\%$ & $O R$ & $95 \% C L$ \\
\hline \multicolumn{5}{|c|}{ Sociodemographic variables: } \\
\hline \multicolumn{5}{|c|}{ Age (years) } \\
\hline$\leqslant 25$ & $33 / 73$ & 45.2 & 4.45 & \multirow[t]{2}{*}{$2.52,7.88$} \\
\hline$>25$ & $20 / 128$ & 15.6 & 1.0 & \\
\hline \multicolumn{5}{|l|}{ Marital status } \\
\hline married, only wife & $27 / 148$ & 18.2 & 0.23 & \multirow[t]{2}{*}{$0.11,0.49$} \\
\hline other & $26 / 53$ & 49.1 & 1.0 & \\
\hline \multicolumn{5}{|l|}{ Education $t$} \\
\hline some & $27 / 86$ & 31.4 & 1.66 & \multirow[t]{2}{*}{$0.93,2.97$} \\
\hline none & $22 / 102$ & 21.6 & 1.0 & \\
\hline \multicolumn{5}{|l|}{ Living children } \\
\hline none & $13 / 46$ & 28.3 & 1.13 & $0.45,2.83$ \\
\hline some & $40 / 155$ & 25.8 & 1.0 & \\
\hline $0-3$ & $51 / 155$ & 32.9 & 10.79 & $3.39,34.35$ \\
\hline$>3$ & $2 / 46$ & 4.4 & 1.0 & \\
\hline Infertile $\neq$ & & & & \\
\hline yes & $13 / 54$ & 24.1 & 0.85 & $0.46,1.57$ \\
\hline no & $40 / 107$ & 27.2 & 1.0 & \\
\hline Uses modern contrac & & & & \\
\hline yes & $8 / 51$ & 15.7 & 0.43 & $0.24,0.78$ \\
\hline no & $45 / 150$ & 30.0 & 1.0 & \\
\hline Sexual/STD history: & & & & \\
\hline Partners in last $12 \mathrm{~m}$ & & & & \\
\hline$>1$ & $9 / 18$ & 50.0 & 3.16 & $0.94,10.63$ \\
\hline $0-1$ & $44 / 183$ & 24.0 & 1.0 & \\
\hline Reported STD ever & & & & \\
\hline yes & $19 / 64$ & 29.7 & 1.28 & $0.64,2.56$ \\
\hline no & $34 / 137$ & 24.8 & 1.0 & \\
\hline Reported STD in las & & & & \\
\hline yes & $13 / 33$ & 39.4 & 2.08 & $1.05,4.13$ \\
\hline no & $40 / 168$ & 23.8 & 1.0 & \\
\hline Gen symp treat $₫$ in la & & & & \\
\hline yes & $4 / 19$ & 21.1 & 0.72 & $0.32,1.66$ \\
\hline no & $49 / 182$ & 26.9 & 1.0 & \\
\hline Partner symptomatic & & & & \\
\hline yes & $6 / 19$ & 31.6 & 1.33 & $0.49,3.56$ \\
\hline no & $47 / 182$ & 25.8 & 1.0 & \\
\hline Current symptoms: & & & & \\
\hline Abnormal vaginal dis & & & & \\
\hline yes & $15 / 45$ & 33.3 & 1.55 & $0.96,2.51$ \\
\hline no & $38 / 156$ & 24.4 & 1.0 & \\
\hline Genital itch & & & & \\
\hline yes & $5 / 19$ & 26.3 & 1.00 & $0.47,2.09$ \\
\hline no & $48 / 182$ & 26.4 & 1.0 & \\
\hline Dysuria & & & & \\
\hline yes & $4 / 20$ & 20.0 & 0.67 & $0.25,1.82$ \\
\hline no & $49 / 181$ & 27.1 & 1.0 & \\
\hline Dyspareunia & & & & \\
\hline yes & $7 / 35$ & 20.0 & 0.65 & $0.29,1.45$ \\
\hline no & $46 / 166$ & 27.7 & 1.0 & \\
\hline Lower abdominal pai & & & & \\
\hline yes & $13 / 44$ & 29.6 & 1.25 & $0.54,2.72$ \\
\hline no & $40 / 157$ & 25.5 & 1.0 & \\
\hline Signs on examination ${ }^{\star}$ & & & & \\
\hline Lower abdominal ten & & & & \\
\hline yes & $7 / 31$ & 22.6 & 0.79 & $0.32,1.93$ \\
\hline no & $44 / 163$ & 27.0 & 1.0 & \\
\hline Abnormal vaginal dis & & & & \\
\hline yes & $38 / 136$ & 27.9 & 1.34 & $0.58,3.08$ \\
\hline no & $13 / 58$ & 22.4 & 1.0 & \\
\hline Vaginal erythema & & & & \\
\hline yes & $30 / 97$ & 30.9 & 1.62 & $0.87,3.03$ \\
\hline no & $21 / 97$ & 21.7 & 1.0 & \\
\hline Visible cervicitis $† \dagger$ & & & & \\
\hline yes & $26 / 70$ & 37.1 & 2.47 & $0.99,6.15$ \\
\hline no & $23 / 119$ & 19.3 & 1.0 & \\
\hline Swab test & & & & \\
\hline positive & $8 / 11$ & 72.7 & 8.98 & $2.71,29.71$ \\
\hline negative & $41 / 179$ & 22.9 & 1.0 & \\
\hline Cervical motion tend & & & & \\
\hline yes & $4 / 16$ & 25.0 & 0.95 & $0.31,2.93$ \\
\hline no & $45 / 173$ & 26.0 & 1.0 & \\
\hline
\end{tabular}

^ Positive for $C$ trachomatis by PCR analysis.

$\dagger 13$ women had missing data on education.

$\ddagger$ Couples were considered infertile if the woman reported that they wanted more children, were trying to conceive, and had had unprotected intercourse for 2 or more years.

Genital symptoms treated in last 3 months, whether perceived as sexually transmitted or not.

${ }^{\star \star}$ Menstruating women $(n=7)$ were excluded in the analysis of findings on examination. Women who had had a hysterectomy $(n=4)$ were excluded in the analysis of cervical and upper tract signs. A further 1 woman had missing data for visible cervicitis and 1 for cervical motion tenderness.

t十Visible cervicitis was defined as erythema or oedema of the zone of ectopy. less common. Overall, $59 \%$ of women had evidence of a current STD.

Results for the univariate associations of potential risk factors/markers with chlamydial and trichomonal infection are shown in tables 3 and 4 respectively. Other variables investigated but not shown included parity and gravidity (similar results to the number of living children); history of genital symptoms over the previous 3 months for each symptom (similar results to those for the corresponding current symptom). Ever use of a condom was also not associated with any of the outcomes. Although having had more than one partner in the previous 3 months was positively associated with each of the outcomes, none was significant. Both the presence of mucopus and cervical friability were most strongly associated with chlamydial infection $(\mathrm{OR}=3.78, \quad 95 \%$ $\mathrm{CL}=0.96, \quad 14.94 ;$ and $\mathrm{OR}=3.75, \quad 95 \%$ $\mathrm{CL}=0.76,18.49$, respectively) although these were not significant.

Chlamydial infection (table 3) was significantly associated with being aged 25 years or less, having fewer than four living children, reporting an STD in the previous 3 months, and having a positive swab test. Being married to a man as the only wife and using modern contraception were associated with reduced risk of chlamydial infection. We also assessed associations between chlamydial infection and the other outcomes (PID, T vaginalis, syphilis, and $\mathrm{BV}$ ), none of which was significant, although both $T$ vaginalis (OR $=1.75,95 \%$ $\mathrm{CL}=0.91,3.36)$ and $\mathrm{BV} \quad(\mathrm{OR}=2.45,95 \%$ $\mathrm{CL}=0.84,7.18)$ had $\mathrm{p}$ values $<0.10$.

In the multivariate models for chlamydial infection, being 25 years or younger and having fewer than four living children were both independently associated with infection, while being married to a man as the only wife was independently protective for all levels of the models. These three were the only significant variables in the "history only" model, with none of the sexual history variables being significant. In the "history and exam" model, a positive swab test was also significant. The full "laboratory" model contained the following variables: age 25 or less $(\mathrm{OR}=2.86,95 \%$ $\mathrm{CL}=1.72,4.75)$, being married as the only wife $(\mathrm{OR}=0.32,95 \% \mathrm{CL}=0.13,0.74)$, having fewer than four living children $(\mathrm{OR}=5.68,95 \%$ $\mathrm{CL}=1.45$, 22.28), a positive swab test $(\mathrm{OR}=4.73,95 \% \mathrm{CL}=1.32,16.88)$, and having $\mathrm{BV}(\mathrm{OR}=4.33,95 \% \mathrm{CL}=1.26,14.88)$. The odds ratios in the earlier multivariate models were similar to those in this final model. No interaction terms were significant.

For trichomonal infection (table 4), marital status and use of modern contraception were again protective as was education; infertility, having no living children, having more than one sexual partner in the previous 12 months, and having had genital symptoms treated in the previous 3 months were associated with infection. None of the symptoms was significant, but most of the signs were. Evaluation of associations with the other outcomes (PID, $C$ trachomatis, syphilis, and BV) revealed a significant association with PID only $(\mathrm{OR}=1.90$, 
Table 4 Univariate associations between sociodemographic data, sexual/STD history, clinical data, and infection with Trichomonas vaginalis, among 198 randomly selected women, Asaro Valley, Papua New Guinea

\begin{tabular}{|c|c|c|c|c|}
\hline & \multicolumn{2}{|c|}{ TV positive* } & \multicolumn{2}{|c|}{ Univariate } \\
\hline & No/total & $\%$ & $O R$ & $95 \% C L$ \\
\hline \multicolumn{5}{|c|}{ Sociodemographic variables: } \\
\hline \multicolumn{5}{|c|}{ Age (years) } \\
\hline$\leqslant 25$ & $33 / 73$ & 45.2 & 0.92 & \multirow[t]{2}{*}{$0.56,1.53$} \\
\hline$>25$ & $59 / 125$ & 47.2 & 1.0 & \\
\hline \multicolumn{5}{|l|}{ Marital status } \\
\hline married, only wife & $60 / 147$ & 40.8 & 0.41 & \multirow[t]{2}{*}{$0.22,0.77$} \\
\hline other & $32 / 51$ & 62.6 & 1.0 & \\
\hline \multicolumn{5}{|l|}{ Education $\dagger$} \\
\hline some & $30 / 84$ & 35.7 & 0.50 & \multirow[t]{2}{*}{$0.30,0.84$} \\
\hline none & $53 / 101$ & 52.5 & 1.0 & \\
\hline \multicolumn{5}{|l|}{ Living children } \\
\hline none & $28 / 45$ & 62.2 & 2.29 & $1.11,4.72$ \\
\hline some & $64 / 153$ & 41.8 & 1.0 & \\
\hline $0-3$ & $77 / 152$ & 50.7 & 2.12 & $0.99,4.54$ \\
\hline$>3$ & $15 / 46$ & 32.6 & 1.0 & \\
\hline Infertile $\ddagger$ & & & & \\
\hline yes & $32 / 53$ & 60.4 & 2.16 & $1.03,4.52$ \\
\hline no & $60 / 145$ & 41.4 & 1.0 & \\
\hline Uses modern contrac & & & & \\
\hline yes & $18 / 51$ & 35.3 & 0.54 & $0.32,0.91$ \\
\hline no & $74 / 147$ & 50.3 & 1.0 & \\
\hline Sexual/STD history: & & & & \\
\hline Partners in last $12 \mathrm{~m}$ & & & & \\
\hline$>1$ & $13 / 18$ & 72.2 & 3.32 & $1.28,8.66$ \\
\hline $0-1$ & $79 / 180$ & 43.9 & 1.0 & \\
\hline Reported STD ever & & & & \\
\hline yes & $32 / 64$ & 50.0 & 1.23 & $0.67,2.27$ \\
\hline no & $60 / 134$ & 44.8 & 1.0 & \\
\hline Reported STD in las & & & & \\
\hline yes & $18 / 33$ & 54.6 & 1.48 & $0.72,3.01$ \\
\hline no & $74 / 165$ & 44.9 & 1.0 & \\
\hline Gen symp treat $₫$ in la & & & & \\
\hline yes & $13 / 19$ & 68.4 & 2.74 & $1.50,5.02$ \\
\hline no & $79 / 179$ & 44.1 & 1.0 & \\
\hline Partner symptomatic & & & & \\
\hline yes & $10 / 19$ & 52.6 & 1.31 & $0.59,2.94$ \\
\hline no & $82 / 179$ & 45.8 & 1.0 & \\
\hline Current symptoms: & & & & \\
\hline Abnormal vaginal dis & & & & \\
\hline yes & $25 / 45$ & 55.6 & 1.60 & $0.83,3.10$ \\
\hline no & $67 / 153$ & 43.8 & 1.0 & \\
\hline Genital itch & & & & \\
\hline yes & $12 / 19$ & 63.2 & 2.12 & $0.62,7.24$ \\
\hline no & $80 / 179$ & 44.7 & 1.0 & \\
\hline Dysuria & & & & \\
\hline yes & $8 / 20$ & 40.0 & 0.75 & $0.25,2.22$ \\
\hline no & $84 / 178$ & 47.2 & 1.0 & \\
\hline Dyspareunia & & & & \\
\hline yes & $16 / 35$ & 45.7 & 0.96 & $0.55,1.69$ \\
\hline no & $76 / 163$ & 46.6 & 1.0 & \\
\hline Lower abdominal pai & & & & \\
\hline yes & $23 / 44$ & 52.3 & 1.35 & $0.67,2.70$ \\
\hline no & $69 / 154$ & 44.8 & 1.0 & \\
\hline Signs on examination $*$ & & & & \\
\hline Lower abdominal ten & & & & \\
\hline yes & $18 / 31$ & 58.1 & 1.76 & $1.12,2.75$ \\
\hline no & $71 / 161$ & 44.1 & 1.0 & \\
\hline Abnormal vaginal dis & & & & \\
\hline yes & $77 / 135$ & 57.0 & 4.98 & $2.17,11.43$ \\
\hline no & $12 / 57$ & 21.1 & 1.0 & \\
\hline Vaginal erythema & & & & \\
\hline yes & $53 / 97$ & 54.6 & 1.97 & $1.15,3.40$ \\
\hline no & $36 / 95$ & 37.9 & 1.0 & \\
\hline Visible cervicitis $\nmid \dagger$ & & & & \\
\hline yes & $40 / 69$ & 58.0 & 2.11 & $1.29,3.46$ \\
\hline no & $47 / 119$ & 39.5 & 1.0 & \\
\hline Swab test & & & & \\
\hline positive & $6 / 11$ & 54.6 & 1.44 & $0.57,3.61$ \\
\hline negative & $81 / 178$ & 45.5 & 1.0 & \\
\hline Cervical motion tend & & & & \\
\hline yes & $10 / 16$ & 62.5 & 2.08 & $1.14,3.79$ \\
\hline no & $77 / 173$ & 44.5 & 1.0 & \\
\hline
\end{tabular}

^Positive for $T$ vaginalis by wet mount ( $\mathrm{n}=198$ as 3 women had missing data).

$\dagger 13$ women had missing data on education.

$\ddagger$ Couples were considered infertile if the woman reported that they wanted more children, were trying to conceive, and had had unprotected intercourse for 2 or more years.

Genital symptoms treated in last 3 months, whether perceived as sexually transmitted or not.

${ }^{\star \star}$ Menstruating women $(n=6)$ were excluded in the analysis of findings on examination. Women who had had a hysterectomy $(n=3)$ were excluded in the analysis of cervical and upper tract signs. A further 1 woman had missing data for visible cervicitis.

t+Visible cervicitis was defined as erythema or oedema of the zone of ectopy.
$95 \% \mathrm{CL}=1.03,3.51)$. Rates of infection were similar for all ages.

The significance of individual predictors for trichomonal infection in the multivariate models changed as more predictors were added to the model. In the "history only" model, having no formal education, infertility, more than one partner in the previous 12 months, and treatment for genital symptoms in the previous 3 months were each independently predictive of trichomonal infection. In the "history and exam" model significant predictors were reported infertility, more than one partner in the previous 12 months, treatment for genital symptoms in the previous 3 months, and the detection of an abnormal vaginal discharge on examination. In the full "laboratory" model, there were six variables: having gone to school $(\mathrm{OR}=0.53,95 \% \mathrm{CL}=0.27,1.04)$, infertility $(\mathrm{OR}=2.61,95 \% \mathrm{CL}=0.93,7.34)$, more than one partner in the previous 12 months $(\mathrm{OR}=3.72,95 \% \mathrm{CL}=1.11,12.48)$, treatment for genital symptoms in the previous 3 months $(\mathrm{OR}=2.98,95 \% \mathrm{CL}=1.63,5.47)$, abnormal discharge on examination ( $\mathrm{OR}=3.91,95 \%$ $\mathrm{CL}=1.47,10.35)$, and infection with $C$ trachomatis (OR=1.88, 95\% $\mathrm{CL}=1.04,3.41)$. Although neither education nor infertility were significant at a $\mathrm{p}$ value $=0.05$, both were very nearly so. Removal of either or both resulted in instability of other variables, and retention of both resulted in a model with better fit as determined by the Hosmer-Lemeshow statistic. ${ }^{11}$ For these reasons they were retained in the final model. No interaction terms were significant.

Finally, we asked married women whether they thought their husband had had sex with another woman in the past 3 months. Of the 163 married women, $51(31 \%)$ said yes, 78 (48\%) said no, and $34(21 \%)$ weren't sure, but thought it was possible. For both STDs, rates of infection were similar among the women who said "yes" and those who said "maybe", but were lower among those who said "no". The rates for $C$ trachomatis were: yes, $29 \%$; maybe $26 \%$; no, $14 \%$. For $T$ vaginalis the rates were: yes, $44 \%$; maybe, $59 \%$; no, 35\%. When stratified by age $(\leqslant 25 v>25)$ these patterns persisted for women over 25 , and were significant in this group for chlamydial infection. For the younger women, the differences were much less marked for both infections, and were not significant.

\section{Discussion}

In this community based study of an apparently "low risk" rural population of women we found an extremely high prevalence of STDs, consistent with previous studies in the Pacific region. In Fiji, $45 \%$ of antenatal clinic attenders were positive for $C$ trachomatis as measured by Chlamydiazyme immunoassay, while only $5.9 \%$ had $T$ vaginalis detected by wet mount. ${ }^{12}$ Klufio et al found a prevalence of chlamydial infection of $17.7 \%$ in a Port Moresby antenatal clinic, with no sociodemographic markers significantly associated with infection. ${ }^{7}$ An earlier study in East New Britain, one of the island provinces of Papua 
New Guinea, found that $44.6 \%$ of "unselected" Melanesian women attending health centres for other purposes had trichomonal infection. ${ }^{13}$

Among the 270 women selected for the study only $75 \%$ completed the protocol, although participation was high among those who attended the preliminary workshop. Relative to the census, younger women (15-19 years old) were underrepresented. One explanation for this is that adolescents were more likely to feel embarrassed and/or to be virgins. If this were the case, the selection bias in this age group would be towards those who were sexually active, and symptomatic. While this may explain some of the missing adolescents, younger women were frequently reported as being absent from the village, but returning soon. Younger women, not bound down by family responsibilities, are more free to visit friends and relatives. Local ethnographic studies suggest that adolescents are frequently sexually active, and that adolescent girls may have many partners, sometimes exchanging sex for goods or for transportation. ${ }^{6}$ Thus, while it is possible that some of the missed adolescent girls were less likely to have STDs, it is also possible that some were at extremely high risk.

Despite the unknown direction of the selection bias in the youngest age group, and the non-participation of some of the women, we believe that the sample in this study provides a reasonable representation of women of reproductive age in rural communities in the Asaro Valley. Given the legendary cultural diversity in Papua New Guinea, generalisation to other areas must be done carefully. Based on behavioural studies which report similar levels of risky behaviour in other parts of the highlands, ${ }^{6}$ it seems reasonable to assume similar levels of infection in areas of the highlands readily accessible by road. In isolated parts of the highlands, and in non-highland areas, the situation may be different. The data from Klufio et $a l^{7}$ indicate at least that the problem is not confined to the highlands.

In this study we found only three women to be infected with $N$ gonorrhoeae, despite high levels of other STDs. This is surprising, but could be due to a number of factors. We could have failed to detect some infections for unknown reasons, despite close monitoring of the methodology. Alternatively, the low prevalence could be genuine, and reflect relatively effective treatment of gonorrhoea. As gonococcal infection is usually symptomatic in men $^{14}$ and as men more frequently use the STD services ${ }^{6}$ it is possible that most men with gonorrhoea are obtaining effective treatment, thus reducing the reservoir of infection and the risk of transmission per sexual act.

For chlamydia, none of the symptoms were significantly associated with infection, even in the univariate analysis. The lack of association with symptoms is well recognised. ${ }^{14}$ The association with reported vaginal discharge may in part be due to concurrent infection with $T$ vaginalis or bacterial vaginosis. Of the clinical signs, only the swab test was significantly asso- ciated with chlamydial infection. Other authors have reported variable performance of clinical signs as predictors of cervical infections, and no one sign has consistently proved useful. ${ }^{15} 16$

The strong association between being 25 years or less and having chlamydial infection is likely to reflect a true association despite the selection bias in the youngest age group. Chlamydial infection was most common in the 20-24 age group, and the risk persists even when the 15-19 age group are excluded. This finding is also consistent with other studies. The relative protection provided by being married to a man as his only wife, compared with any other marital status, is also not surprising assuming that both partners are faithful. Given the strength of the association found, it appears that this is probably the case for many. None the less, $18 \%$ of "only wives" were infected with $C$ trachomatis. In this community it is relatively acceptable for men to have extramarital partners, while it is completely unacceptable for women to do so. Interestingly, in women over 25 their perception of their husband's behaviour corresponded significantly with infection, while in younger women the correlation was poor. This may reflect a difference in the behaviour of younger women, a difference in their understanding of their husband, or more residual infection in either husband or wife, in this age group.

The association between trichomonal infection and marital status provides further evidence of the protective effect of being an only wife. Again, however, infection was very common even among this group. The high rates of infection found in all age groups may reflect rates of acquisition, non-recognition of symptoms, lack of treatment seeking, and prevailing treatment regimens, as well as the natural history of infection. Untreated, trichomoniasis in women is thought to persist indefinitely, although it is usually transient in men. ${ }^{14}$ Despite $43 \%$ of the women reporting symptoms at the time of the survey, only $9.5 \%$ had sought treatment in the previous 3 months. Many women claimed not to have recognised the significance of their symptoms until our workshop. Even following this, relatively few of those with an abnormal discharge found on examination had reported it in the interview. Moreover, at the time of the study recommended standard treatment for vaginal discharge involved treatment for gonococcal and chlamydial infection first, with treatment for trichomoniasis only for treatment failures. In this light, the increased risk of trichomonal infection associated with treatment in the previous 3 months is not surprising, as treatment seeking is likely to be ineffective in eradicating the infection. The age distribution, as well as the high prevalence, may thus reflect untreated infection acquired at any age but persisting because of lack of appropriate treatment.

The association of trichomonal infection with signs of vaginitis is expected, while the lack of association with symptoms presumably reflects poor symptom recognition. Of interest is the association with upper tract signs and 
infertility, with infertility being independently associated with trichomonal infection in all models. This is not likely to be due to confounding by other sexually transmitted organisms, as the association persisted when chlamydial and/or gonococcal infections were controlled for (data not shown), and chlamydial cervicitis was not associated with upper tract signs in our population. Alternatively, the association may be due to either trichomoniasis being a risk for PID and subsequent infertility, or infertility being a risk for trichomoniasis because of either the husband or wife in an infertile couple seeking alternative partners for reproduction.

Trichomoniasis may be associated with abdominal pain ${ }^{14}$ and has been implicated in "atypical" PID in infertile women. ${ }^{17}$ Trichomonads have been cultured from the fallopian tubes and pouch of Douglas; and bacteria have been demonstrated to be attached to $T$ vaginalis in vitro. ${ }^{18}$ Postulating that trichomonal infection may facilitate the ascent of $C$ trachomatis, Paisarntantiwong et al studied the risk of developing clinical PID among women infected with $C$ trachomatis. ${ }^{19}$ They reported an increased risk of upper tract disease in women coinfected with $T$ vaginalis after controlling for other relevant factors. Thus there is suggestive evidence that trichomonal infection may be implicated in upper tract disease and infertility. However, it does not preclude the possibility of a behavioural component to the association. A common reason given for a man taking a second wife is that the first is infertile and as polygynous marriages were associated with trichomonal infection in our population $(64 \%$ of co-wives compared with $41 \%$ of only wives), this may be a contributing factor. Given the high prevalence of infertility, chlamydial, and trichomonal infections in this population, further work should be done to explore this relation.

Having more than one sexual partner in the previous year was significantly associated with trichomonal infection, and was almost significant as a univariate predictor of chlamydial infection. However, when stratified by age $(\leqslant 25$ versus $>25)$ or by marital status (married as the only wife versus other status), it becomes clear that this effect is mediated by the younger women, and by those who are not only wives.

As Papua New Guinea is undergoing rapid social change, and as it was mainly women 25 years of age or less who reported more than one partner in the previous year, we tried to assess whether this was a true age effect or a cohort effect, by looking at the lifetime number of sexual partners reported by the women by age group (data not previously shown). The lifetime number of partners increases from a median of 4.5 in those aged $15-19$, to 5.5 in those aged $20-24$, then gradually declines to 1.0 for those over 40 years of age (KruskalWallis $\mathrm{H}=27.482,5 \mathrm{df}, \mathrm{p}$ value $<0.001)$. Although reporting of sexual partners has a number of limitations, this apparent change towards increasing numbers of sexual partners in the younger age groups is consistent with sociocultural changes in the area. Thus, even if the numbers are not precise, the trend is probably real, suggesting that some of the differences in behaviour are due to a cohort effect.

Condom use was extremely low in this group of women, with only $7.5 \%$ reporting ever having used a condom. With the current gender based power structure, male condoms are not likely to be a successful means of protection for the majority of women. An acceptability study of the female condom in urban areas showed that some women found them quite acceptable and would continue to use them, ${ }^{6}$ and there may be a role for the female condom in STD and HIV prevention in Papua New Guinea.

Because of the extraordinarily high prevalence of STDs in an apparently "low risk" population of rural women, with relatively little recognition of their symptoms or their implications, low utilisation of curative services, and low use of condoms, the risk per sexual act in this population is high. There is thus a compelling argument for urgent and effective interventions to reduce this burden rapidly both to alleviate suffering caused by these infections and their sequelae, and to reduce the rapid transmission of HIV.

We thank the Special Programme of Research, Development and Research Training in Human Reproduction, of the World Health Organisation, for financial assistance for this research.
We particularly thank Dr Patrick Rowe of HRP for his ongoing We particularly thank Dr Patrick Rowe of HRP for his ongoing
enthusiasm and support for our work. We are grateful to Dr John enthusiasm and support for our work. We are grateful to Dr John
Neuhaus from the University of California, San Francisco for statistical advice; to Dr Nancy Padian from the University of California, San Francisco; Dr Arthur Reingold and Dr Janneke van de Wijgert from the University of California, Berkeley; and Dr Deborah Lehmann from the Papua New Guinea Institute of Medical Research, for advice and encouragement during various stages of this study, and for helpful comments on earlier various stages of this study, and for helpful comments on earlier to the women and men of the Asaro Valley who participated in this study.

1 Wasserheit JN. Epidemiological synergy. Interrelationships between human immunodeficiency virus infection and other sexually transmitted diseases. Sex Transm Dis 1992;19:61-77.

2 Laga $M$, Manoka A, Kivuvu $M$, et al. Non-ulcerative sexually transmitted diseases as risk factors for HIV-1 transmission in women: results from a cohort study. AIDS 1993; 7:93-102

3 Laga M, Alary M, Nzila N, et al. Condom promotion. STD treatment leading to a declining incidence of HIV-1 infectreatment leading to a declining incidence of HIV-1 infec-
tion in female Zairena sex workers. Lancet 1994;344:246-8 tion in female Zairena sex workers. Lancet 1994;344:246-8.
Grosskurth H, Mosha F, Todd J, et al. Impact of improved treatment of sexually transmitted diseases on HIV infection in rural Tanzania: randomised controlled trial. Lancet 1995;346:530-6.

5 Central Public Health Laboratory. Papua New Guinea National HIV Reference Laboratory Annual Report, 1996. Boroko, NCD, Papua New Guinea, February 1997 (Unpublished report.)

6 Jenkins C, Passey M. Sexually transmitted diseases in Papua New Guinea. In: Brown $\mathrm{T}$, Chan R, Mugriditchian D, Mulhall B, Plummer D, Sittitrai W, eds. Sexually transmitted diseases in Asia and the Pacific. Melbourne, Venereology, 1997.

7 Klufio CA, Amoa AB, Delamare O, Kariwiga G. Endocervical Chlamydia trachomatis infection in pregnancy: direct test and clinico-sociodemographic survey of pregnant patients at the Port Moresby General Hospital antenatal clinic to determine prevalence and risk markers. Aust NZ $\mathscr{f}$ Obstet Gynaecol 1992;32:43-6.

8 Brunham RC, Paavonen J, Stevens CE et al. Mucopurulen cervicitis: the ignored counterpart in women of urethritis in men. N Engl f Med 1984;311:1-6.

9 Hayes JL, Bailey RB, Mabey DCW, et al. Genotyping of Chlamydia trachomatis from a trachoma-endemic village in The Gambia by a nested polymerase chain reaction: identification of strain variants. F Infect Dis 1992;166:1173-7.

10 Liang K-Y, Zeger SL. Longitudinal data analysis using generalised linear models. Biometrika 1986;73:13-22.

11 Hosmer DW, Lemeshow S. Applied logistic regression. 1st ed. New York: Wiley, 1989.

12 Gyaneshwar R, Nsanze H, Singh KP, Pillay S, Seruvatu I. The prevalence of sexually transmitted disease agents in pregnant women in Suva. Aust NZ J Obstet Gynaecol 1987; 27:213-5. 
13 Zigas V. An evaluation of trichomoniasis in two ethnic groups in Papua New Guinea. Sex Transm Dis 1977;4:63-5.

14 Jones $\mathrm{RB}$, Wasserheit $\mathrm{JN}$. Introduction to the biology and natural history of sexually transmitted diseases. In: Wasserheit JN, Aral SO, Holmes KK, Hitchcock PJ, eds. Research issues in human behaviour and sexually transmitted diseases in the AIDS era. Washington DC: American Society for Microbiology, 1991.

15 Vuylsteke B, Laga M, Alary M, et al. Clinical algorithms for the screening of women for gonococcal and chlamydial infection: evaluation of pregnant women and prostitutes in Zaire. Clin Infect Dis 1993;17:82-8.
16 Mayaud P, Grosskurth $\mathrm{H}$, Changalucha J, et al. Risk assessment and other screening options for gonorrhoea and chlamydial infections in women attending rural Tanzanian antenatal clinics. Bull WHO 1995;73:621-30.

17 Cates W, Joesoef MR, Goldman MB. Atypical pelvic inflammatory disease: can we identify clinical predictors? $A m \mathcal{F}$ Obstet Gynecol 1993;169:341-6.

18 Keith LG, Berger DS, Edelman DA, et al. On the causation of pelvic inflammatory disease. Am F Obstet Gynecol 1984; 149:215-24.

19 Paisarntantiwong R, Brockman S, Clarke L, et al. The relationship of vaginal trichomoniasis and pelvic inflammatory disease among women colonized with Chlamydia trachomatis. Sex Transm Dis 1995;22:344-7.

\section{Gonorrhoea and the balsams}

Historical vignette
Balsams are aromatic oleoresins obtained from plants, usually trees. In the past they were widely used both topically as cosmetics and rubefacients and internally as expectorants. A subgroup of balsamics were thought to be of value for urogenital disinfection and particularly for gonorrhoea; the best known of these were the oils of copaiba, cubebs, buchu, and sandalwood. Chemically they resemble each other closely; they are readily absorbed and excreted, partly by the lungs but chiefly by the kidneys, and all are gastrointestinal irritants.

Herbal preparations had always been a part of the treatment of gonorrhoea, and in the 18th century balsams were often prescribed for this purpose. In Europe, copaiba was the most familiar; it was mentioned by both Hunter and Bell. Obtained from the bark of Copaifera, a native of Brazil, it was regarded as a valuable drug. A writer in the Lancet in 1820 stated that "if there is anything certain in therapeutics it is the action of copaiba in cases of gonorrhoea; all the practitioners whom I have consulted are unanimous in this opinion." Among these was Philippe Ricord, the doyen of French venereologists, who maintained that it was a "specific" in urethral blennorrhagia (gonorrhoea). Although some physicians, including Ricord, recommended that it should be used early in an attack, supplementing urethral injections, the majority deferred its use until the acute symptoms had subsided; it was regarded as particularly effective for the treatment of gleet (post-gonococcal urethritis).

Unfortunately, the side effects of copaiba were formidable. It smelt and tasted horrible, and often caused gastroenteritis, headache, stomatitis, and flushes. Since the balsam was partly excreted in the breath, the nature of the patient's complaint was only too obvious to others. Ricord lightly dismissed these effects as "inconveniences", but they were very unpleasant, and only slightly mitigated by enclosing the oil in gelatin capsules or between sheets of wafer paper. Nevertheless, the French were emphatic that copaiba was so effective that the side effects were worth enduring. Most British surgeons continued to rely on the traditional purging, bleeding, and urethral irrigations in the acute phase of gonorrhoea and, despite its disadvantages, administered copaiba later. However, an alternative appeared in the form of cubebs, the fruit of a pepper vine, Piper cubeba, which grew in Java. Its introduction to Europe was said to have come about after an officer in the Indian army, sailing down the Ganges, developed an intractable gonorrhoea which failed to respond to the usual treatments. One of his servants proposed cubebs, and he used it with success. He related this to the surgeon of his corps in Java, by whom it was prescribed and eventually reported to England. It was soon realised that the effect of cubebs on gonorrhoea was similar to that of copaiba but the side effects were less severe, which was a great advantage. Although some observers were doubtfulabout its efficacy, others were enthusiastic. Sir Astley Cooper wrote: "There is now no surgeon of the least experience who does not acknowledge that it is a very powerful remedy for this disease (gonorrhoea). A short time ago it was imported in only very small quantities, but now whole shiploads of it are annually brought to the port of London."

Cubebs was usually given alone without urethral injections, although other oral medication might be added. Henry Jeffreys, a surgeon at the London Lock Hospital, reported that symptoms improved within 48 hours, and that cure should follow in five or six days; the possibility of later appearance of gleet was much reduced. In one of his student lectures Astley Cooper gave a vivid testimonial: "a gentleman came to me and said that as he was going to give a large dinner party and would be obliged to drink a great deal of wine, he wished to be cured of clap immediately. I told him I could not promise this but I would, if he liked, offer a remedy which a gentleman from Java had used with great success. He said he would try it and he should prefer it to the balsam of copaiba, of which the people in his house knew the smell (laughter). He took two doses four times a day for eight days, and the discharge did not return."

Sandalwood oil was the last of the balsams to be introduced. It was distilled from the heartwood of Santalum album, which grows in the East Indies. Its action was similar to that of copaiba, but its odour and taste were less unpleasant and it was only a mild gastrointestinal irritant. Although it was expensive, it soon replaced copaiba and cubebs, and was widely used for the subacute stage of gonorrhoea, cystitis, and gleet. It remained highly regarded until potassium permanganate came into use in 1892. It was not abandoned even then. In 1950, Harkness noted that before antibiotics were discovered sandalwood oil lessened the discharge of acute gonorrhoea, was highly effective in acute abacterial urethritis, and seemed to have a soothing effect in acute prostatitis, endourethral herpes, and traumatic urethritis.

Copaiba, cubebs, and sandalwood oil remained in the British Pharmaceutical Codex until 1963, sometimes alone and sometimes in combination with each other. It is difficult to find a rationale for their long continued use. None of the balsams showed any in vitro activity against Neisseria gonorrhoeae, although sandalwood oil had a slight action against staphylococci. Their efficacy in gonorrhoea was sometimes ascribed to their lessening the inflammatory reaction, perhaps through an astringent effect on the urethral mucosa; clearly it was not due to antiseptic action. It is tempting to dismiss the balsams out of hand, but they were regularly prescribed for urethritis for over 150 years. Unfortunately, there was no evidence based medicine then to settle the matter. 